\title{
Nanostructured Dielectric Layer for Ultrathin Crystalline Silicon Solar Cells
}

\author{
Yusi Chen, ${ }^{1}$ Yangsen Kang, Jieyang Jia, ${ }^{1}$ Yijie Huo, ${ }^{1}$ Muyu Xue, ${ }^{2}$ Zheng Lyu, ${ }^{1}$ Dong Liang, ${ }^{3}$ \\ Li Zhao, ${ }^{2}$ and James S. Harris ${ }^{1,3,4}$ \\ ${ }^{1}$ Department of Electrical Engineering, Stanford University, Stanford, CA 94305, USA \\ ${ }^{2}$ Department of Material Science and Engineering, Stanford University, Stanford, CA 94305, USA \\ ${ }^{3}$ Department of Physics, Stanford University, Stanford, CA 94305, USA \\ ${ }^{4}$ Department of Applied Physics, Stanford University, Stanford, CA 94305, USA
}

Correspondence should be addressed to James S. Harris; jharris@stanford.edu

Received 18 November 2016; Revised 5 March 2017; Accepted 22 March 2017; Published 16 May 2017

Academic Editor: Sanjay K. Srivastava

Copyright (c) 2017 Yusi Chen et al. This is an open access article distributed under the Creative Commons Attribution License, which permits unrestricted use, distribution, and reproduction in any medium, provided the original work is properly cited.

\begin{abstract}
Nanostructures have been widely used in solar cells due to their extraordinary photon management properties. However, due to poor pn junction quality and high surface recombination velocity, typical nanostructured solar cells are not efficient compared with the traditional commercial solar cells. Here, we demonstrate a new approach to design, simulate, and fabricate whole-wafer nanostructures on dielectric layer on thin c-Si for solar cell light trapping. The optical simulation results show that the periodic nanostructure arrays on dielectric materials could suppress the reflection loss over a wide spectral range. In addition, by applying the nanostructured dielectric layer on $40 \mu \mathrm{m}$ thin $\mathrm{c}-\mathrm{Si}$, the reflection loss is suppressed to below $5 \%$ over a wide spectra and angular range. Moreover, a c-Si solar cell with $2.9 \mu \mathrm{m}$ ultrathin absorber layer demonstrates $32 \%$ improvement in short circuit current and $44 \%$ relative improvement in energy conversion efficiency. Our results suggest that nanostructured dielectric layer has the potential to significantly improve solar cell performance and avoid typical problems of defects and surface recombination for nanostructured solar cells, thus providing a new pathway towards realizing high-efficiency and low-cost c-Si solar cells.
\end{abstract}

\section{Introduction}

Nanostructures have been widely applied onto solar cells, as they demonstrate promising features for future highefficiency and low-cost solar cells, such as antireflection and light trapping [1-7]. However, how to effectively realize the potential of nanostructured solar cells still remain a challenge. Compared with traditional commercial counterparts, nanostructured solar cells have lower energy conversion efficiency [8].

On the other hand, ultrathin crystalline silicon (c-Si) solar cells have attracted much interest, as they could potentially achieve high efficiency with low-cost manufacturing $[9,10]$. However, due to the intrinsic optical properties of $\mathrm{Si}$ as an indirect bandgap material, light trapping using nanostructures is necessary for ultrathin c-Si solar cells to achieve competitive efficiencies [11-14]. In order to get high efficiency, reducing recombination, especially surface recombination, is critical for ultrathin $\mathrm{c}-\mathrm{Si}$ solar cells $[11,12]$. However, typical nanostructured c-Si solar cells suffer from nanostructured pn junction with poor junction quality and high surface damage due the fabrication process, which result in a low $V_{\mathrm{oc}}$, despite a relatively high short circuit current $J_{\mathrm{sc}}$ [11-14]. Consequently, the efficiencies of ultrathin c-Si cells are low.

Such problems can be solved in III-V solar cells by nanostructuring the semiconductor window layer with higher energy bandgap instead of nanostructuring the solar cell absorber. The nanostructured window layer could produce antireflection and light-trapping effect, while at the same time maintaining the pn junction quality and blocking the minority carriers from being recombined 
at the surface [6]. Similarly, this concept could be applied to c-Si solar cells as well. Particularly, low-cost dielectric materials with large bandgap (above $3 \mathrm{eV}$ ) have already been widely used in c-Si solar cells, such as silicon nitride $\left(\mathrm{SiN}_{\mathrm{x}}\right)$, aluminum oxide $\left(\mathrm{Al}_{2} \mathrm{O}_{3}\right)$, and silicon dioxide $\left(\mathrm{SiO}_{2}\right)$ [15]. In addition, these dielectric materials have been reported to provide excellent surface passivation for $\mathrm{c}-\mathrm{Si}$ solar cells [16, 17]. Therefore, by nanostructuring those dielectric materials, antireflection and light trapping could be achieved without sacrificing the junction quality and surface passivation.

In this work, we present the design of nanostructured dielectric layer (NDL) of $\mathrm{SiN}_{\mathrm{x}}$ on c-Si thin films for antireflection and light trapping. Simulation and experiment results are also provided and discussed. First, simulation results demonstrate the design robustness and the photon management performance of the NDL over a wide spectra and angular range. Second, NDL is applied onto a $40 \mu \mathrm{m}$ c-Si thin film, which suppresses the overall reflection to below $5 \%$. In the final part, the NDL is integrated with a c-Si solar cell with $2.9 \mu \mathrm{m}$ ultrathin absorber layer, demonstrating $32 \%$ improvement in $J_{\text {sc }}$ and $30 \mathrm{mV}$ enhancement in $V_{\text {oc }}$.

\section{Design and Simulation of Nanostructured Dielectric Layer}

To study the antireflection effect of nanostructured dielectric layers, optical simulations were performed by finitedifference time-domain (FDTD) method in FDTD Solutions from Lumerical Inc. The simulated nanostructures were an array of nanocones with a $600 \mathrm{~nm}$ diameter at the base and $600 \mathrm{~nm}$ height, as illustrated in Figure 1. In this simulation, the light source was located above the nanostructures, which is incident normally into the nanostructures. The reflectance of each wavelength was calculated based on the ratio of reflected power and the total incident power. As we are only studying the antireflection effect, the c-Si layer under the NDL is assumed to be infinite. A $10 \mathrm{~nm}$ thick $\mathrm{SiO}_{2}$ (index of 1.6) passivation layer is also included beneath the $\mathrm{SiN}_{\mathrm{x}}$ region. When the light comes through the NDL and into the solar cell, reflection occurs at the air/NDL and NDL/ c-Si interfaces. The tapper-shaped nanocones provide a gradually changing refractive index and eliminate the reflection at the air/NDL interface. On the other hand, although the index mismatch between dielectric and c-Si exists, $\mathrm{SiN}_{\mathrm{x}}$ with refractive index $\sim 2$ can suppress the reflectance to below $8 \%$.

Figure 2(a) shows the simulated spectral reflectance of $\mathrm{SiN}_{\mathrm{x}}$ NDL with refractive index ranging from 1.9 to 2.2 . The predicted reflectance is below $10 \%$ over a wide portion of the solar spectrum. Another benefit of nanostructures is their wide acceptance angle. Figure 2(b) shows the comparison of simulated spectral averaged reflectance, which is the integrated reflectance weighted by the number of incident photons per wavelength over AM 1.5G, between the $\mathrm{SiN}_{\mathrm{x}}$ $\mathrm{NDL}$, single-layer antireflective coating (SLARC, $80 \mathrm{~nm}$ thick $\mathrm{SiN}_{\mathrm{x}}$ ), and double-layer antireflective coating (DLARC). In the simulation, the SLARC was set to be single $80 \mathrm{~nm}$ thick

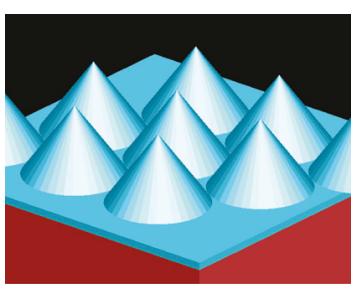

(a)

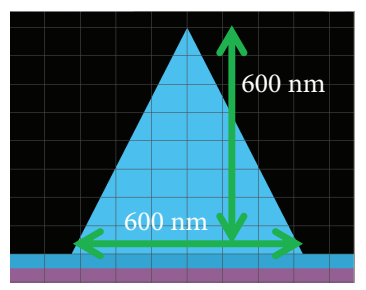

(b)
FIGURE 1: Schematics of simulated NDL on top of c-Si, including (a) top view and (b) cross section.

$\mathrm{SiN}_{\mathrm{x}}$ layer, and the DLARC was $140 \mathrm{~nm}$ thick $\mathrm{SiO}_{2}$ on top of $80 \mathrm{~nm}$ thick $\mathrm{SiN}_{\mathrm{x}}$. The $\mathrm{SiN}_{\mathrm{x}}$ NDL with refractive index of 2.1 shows below $10 \%$ overall reflectance up to 60-degree incidence, which is better than any single-layer antireflective coating (SLARC) at all angles and outperforms double-layer antireflective coating (DLARC) when the incident angle is greater than 20 degrees. On the other hand, the antireflection performance does not change much for NDL with different refractive index from 1.9 to 2.2, which provides a good design robustness as $\mathrm{SiN}_{\mathrm{x}}$ might have a variation in refractive index.

\section{Fabrication of Nanostructured Dielectric Layer}

The $\mathrm{SiN}_{\mathrm{x}}$ NDL was fabricated using a nanosphere lithography method [18] as shown in Figure 3. First, $700 \mathrm{~nm}$ of $\operatorname{SiN}_{\mathrm{x}}$ with $10 \mathrm{~nm}$ of $\mathrm{SiO}_{\mathrm{x}}$ on top was deposited on the c-Si layer using plasma-enhanced chemical vapor deposition (PECVD) at $350^{\circ} \mathrm{C}$. It should be noted that the $10 \mathrm{~nm}$ of $\mathrm{SiO}_{\mathrm{x}}$ is crucial here for the etching uniformity during the nanosphere lithography process. Next, $600 \mathrm{~nm}$ silica nanospheres were assembled into monolayer closed-pack film on top of the $\mathrm{SiO}_{\mathrm{x}}$ via Langmuir-Blodgett (LB) coating method [19]. Later, with the silica nanospheres as etch masks, electron cyclotron resonance plasma etching with $\mathrm{CF}_{4}$ and $\mathrm{O}_{2}$ gas $\left(\mathrm{CF}_{4}: \mathrm{O}_{2}=10: 1\right)$ is used to etch down the $\mathrm{SiN}_{\mathrm{x}}$ and produce the nanocone arrays. To achieve isotropic etching for the nanostructures, a high chamber pressure of 40 to $50 \mathrm{mTorr}$ was used $[20,21]$. Finally, silica nanosphere residues were removed in 50:1 hydrofluoric acid. The shape of nanostructures can be controlled by the ratio between etchant gas and the bias applied during plasma etching. Scanning electron microscope (SEM) images in Figure 4 shows the fabricated nanocone array with different shapes.

\section{Nanostructured Dielectric Layer on $40 \mu \mathrm{m}$ c-Si Layer}

To evaluate the antireflection and light-trapping effect, a $\mathrm{SiN}_{\mathrm{x}}$ NDL layer was applied onto a $40 \mu \mathrm{m}$ c-Si thin layer that was prepared using the epi-lift-off (ELO) kerfless Si technique. The NDL layer was fabricated using the method described in Section 3 and has the nanodome shape as in Figure 4(a). The reflectance measurements were performed using a standard integrating sphere system, and the characterization results are shown in Figure 5. Figure 5(a) shows the FDTD 


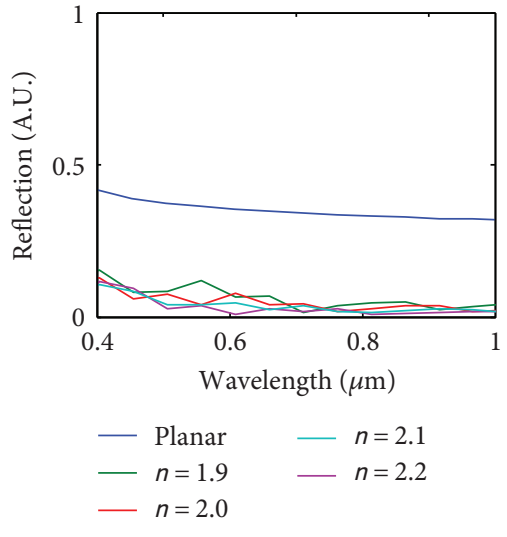

(a)

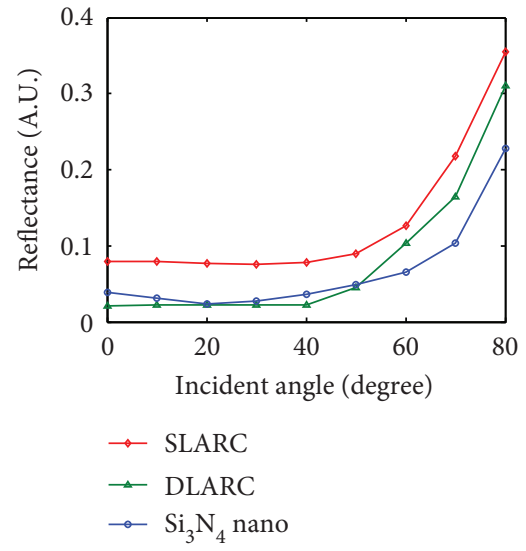

(b)

Figure 2: Simulated antireflection properties of $\operatorname{SiN}_{\mathrm{x}}$ NDL. (a) Spectral reflectance of $\operatorname{SiN}_{\mathrm{x}}$ NDL with refractive index from 1.9 to 2.1 and normal incident light from $300 \mathrm{~nm}$ to $900 \mathrm{~nm}$. (b) Simulation result of integrated overall angular reflectance under AM 1.5G of SLARC (red), DLARC (green), and $\mathrm{SiN}_{\mathrm{x}} \mathrm{NDL}$ with reflective index of 2.1 (blue).

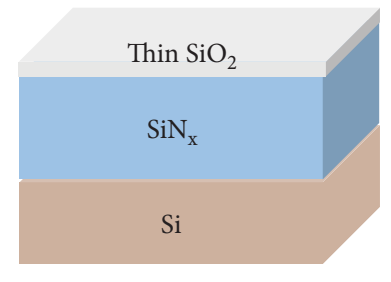

(a)

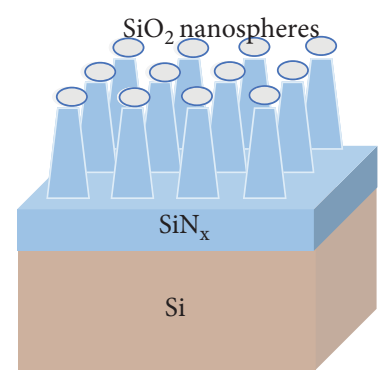

(c)

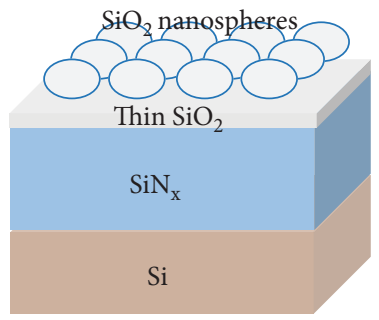

(b)

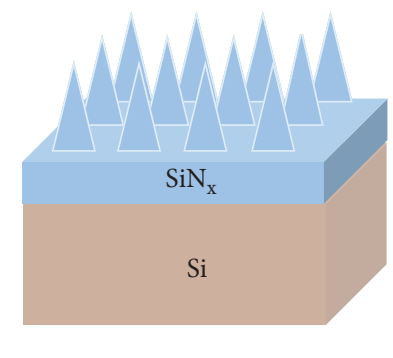

(d)
Figure 3: Fabrication process of the $\operatorname{SiN}_{\mathrm{x}}$ NDL. (a) Deposit the $\mathrm{SiN}_{\mathrm{x}}$ layer on the $\mathrm{c}-\mathrm{Si}$, with a thin layer of $\mathrm{SiO}_{\mathrm{x}}(\sim 10 \mathrm{~nm})$ on top using PECVD; (b) assemble a monolayer of silica nanospheres on top using LB coating method; (c) dry etch the $\mathrm{SiN}_{\mathrm{x}}$ with the silica nanospheres as etching masks; and (d) remove the remaining silica nanospheres and $\mathrm{SiO}_{\mathrm{x}}$ using wet etch.

simulation and experimental measurement results of reflectance on top of the $40 \mu \mathrm{m} \mathrm{c}$-Si thin layer with NDL. The incident light is under normal direction with wavelength ranging from $400 \mathrm{~nm}$ to $1000 \mathrm{~nm}$. From Figure 5(a), the reflectance loss has been suppressed to below $5 \%$ over a wide portion of the solar spectrum, from $400 \mathrm{~nm}$ up to $850 \mathrm{~nm}$. Above $850 \mathrm{~nm}$, the reflectance increases for both simulation and measurement results. This is because the optical absorption in $\mathrm{c}-\mathrm{Si}$ is weak in this wavelength range [22]. The difference between simulation and experiment results at

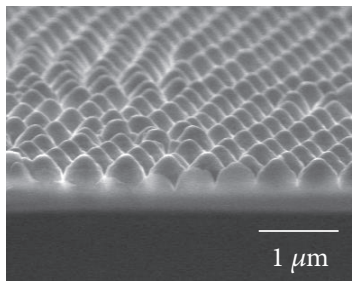

(a)

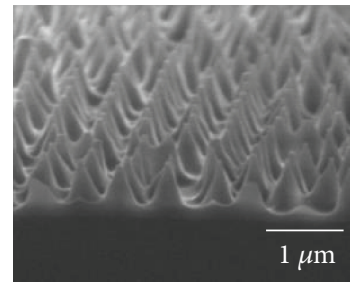

(b)
FIGURE 4: The SEM images of the fabricated NDL with (a) nanodome shape and (b) nanocone shape.

$900 \mathrm{~nm}$ to $1000 \mathrm{~nm}$ mainly comes from the different bottom interface configuration. In simulation, the $40 \mu \mathrm{m} \mathrm{c}$-Si thin layer is a free-standing thin film and the bottom surface is expose to air with large refractive index mismatch. Therefore, the unabsorbed light gets partially reflected at the bottom surface of $\mathrm{c}$-Si. Such reflected light is reflected again at the front $\mathrm{SiN}_{\mathrm{x}} / \mathrm{c}-\mathrm{Si}$ interface and the $\mathrm{SiN}_{\mathrm{x}} /$ air interface. The $40 \mu \mathrm{m}$ thin Si acts like a resonant cavity in this case, generating the resonant peaks between $900 \mathrm{~nm}$ to $1000 \mathrm{~nm}$ in Figure 5(a). On the other hand, in experiment, the sample was placed on a thick polymer layer $(\sim 1 \mathrm{~mm})$ for handling. Therefore, the reflection from the back surface is not strong enough to generate such resonant peaks as in the simulation results. Figure 5(b) shows the measured integrated reflection at different incident angles. The spectral averaged reflection has been suppressed from $\sim 30 \%$ to below $10 \%$ up to 60 -degree incident angle, demonstrating a wide-angle antireflection effect.

\section{Nanostructured Dielectric Layer on Ultrathin c-Si Solar Cells}

To better assess the performance of NDL, a c-Si solar cell with $2.9 \mu \mathrm{m}$ ultrathin absorber was fabricated and integrated with NDL [23]. The fabrication process is shown in Figure 6. 


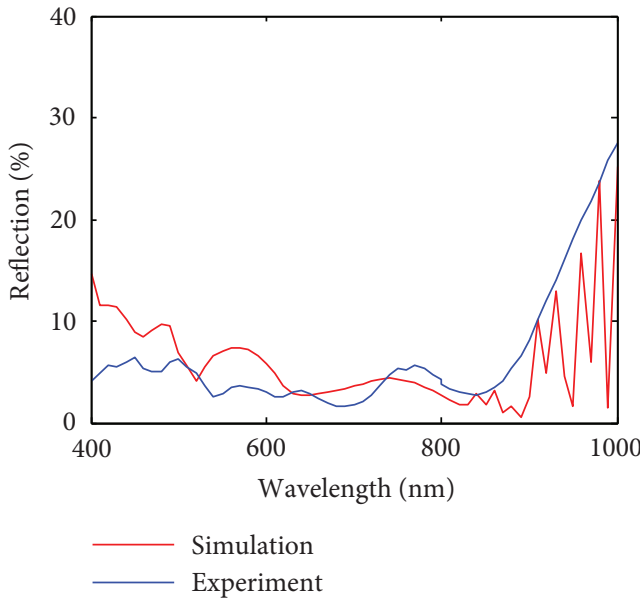

(a)

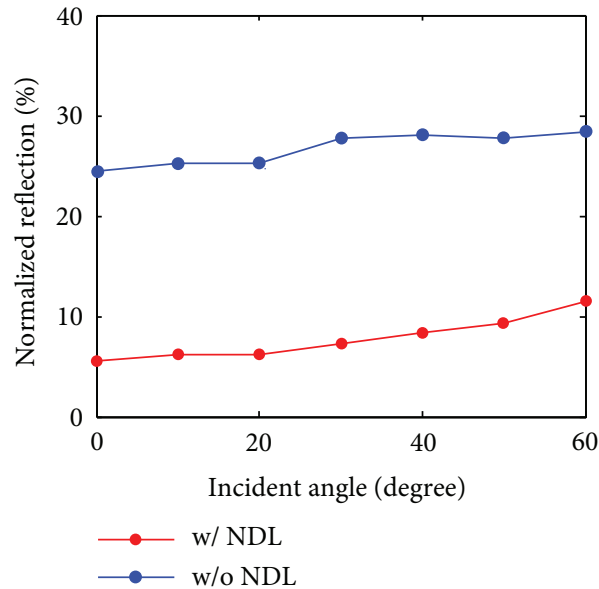

(b)

FIgure 5: (a) The simulation and experiment results of reflection for NDL on $40 \mu \mathrm{m}$ thick unpolished c-Si. The incident light is at normal direction with wavelength ranging from $400 \mathrm{~nm}$ to $1000 \mathrm{~nm}$. (b) The dependence of spectral averaged reflection (400 nm to $1000 \mathrm{~nm}, \mathrm{AM} 1.5 \mathrm{G})$ on incident angle for fabricated NDL on unpolished $40 \mu \mathrm{m} \mathrm{c}$-Si.
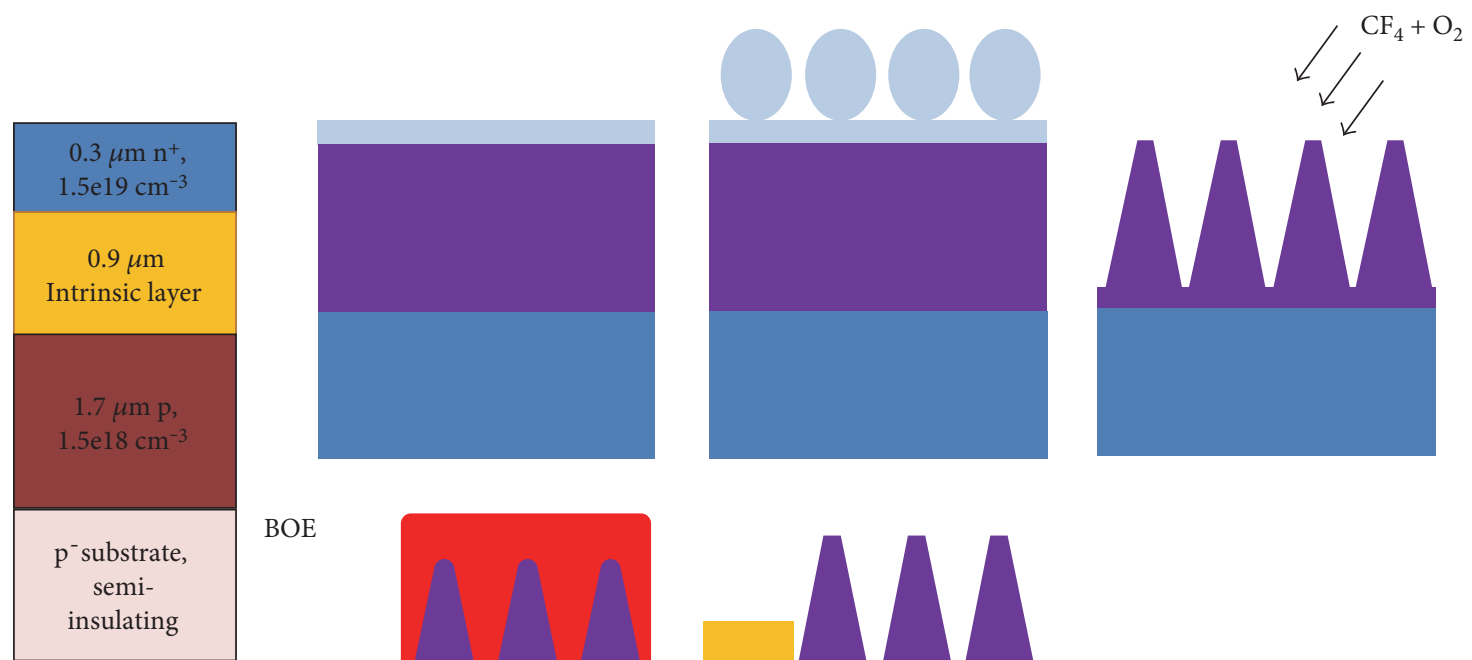

BOE
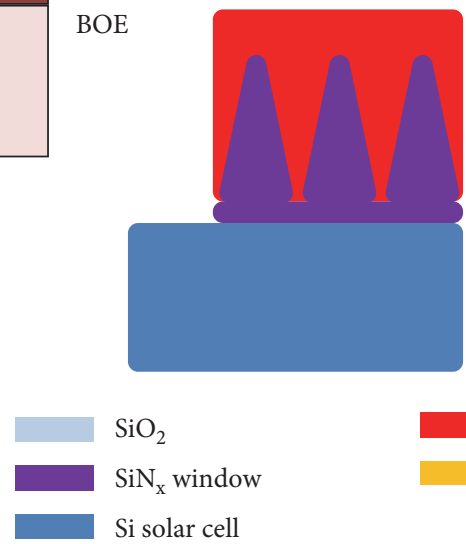

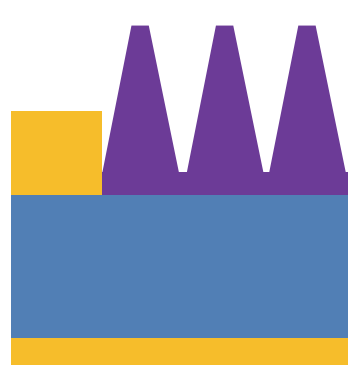

Photoresist

Metal contact

FIgURE 6: Schematics of the fabrication process of ultrathin c-Si solar cells with NDL on top. (a) Deposit a c-Si solar cell with ultrathin absorber on a semi-insulating substrate using RPCVD; (b) deposit the $\mathrm{SiN}_{\mathrm{x}}$ layer and thin $\mathrm{SiO}_{\mathrm{x}}$ layer on c-Si solar cell; (c) assemble a monolayer of silica nanospheres on top; (d) dry etch the $\mathrm{SiN}_{\mathrm{x}}$ layer to form the NDL; (e) use lithography and wet etching of $\mathrm{SiN}_{\mathrm{x}}$ in $6: 1$ BOE to define the top contact region; and (f) create front and back metal contacts.

For comparison, a control sample was fabricated using similar process but without the NDL on top.

First, the ultrathin c-Si solar cell was deposited on top of $\mathrm{a} \sim 100 \Omega \cdot \mathrm{cm}$ semi-insulating $\mathrm{p}^{-} \mathrm{CZ}$ substrate using reduced pressure chemical vapor deposition (RPCVD) in an Applied Materials Epi2 system (Figure 6(a)). The deposition was at $1000^{\circ} \mathrm{C}$ using dichlorosilane (DCS), and phosphine $\left(\mathrm{PH}_{3}\right)$ and diborane $\left(\mathrm{B}_{2} \mathrm{H}_{6}\right)$ were used as the dopants. The solar cell 


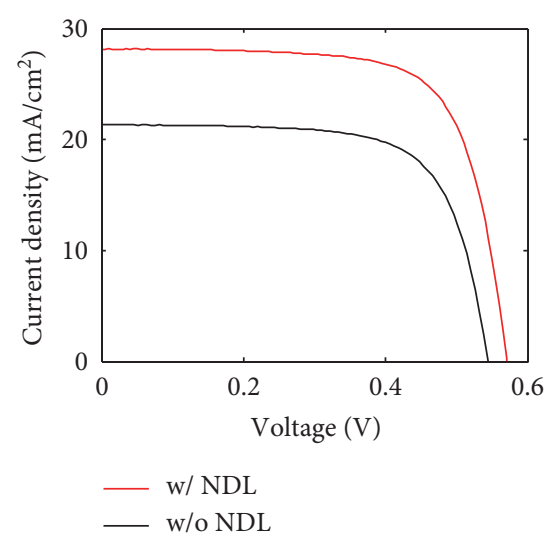

(a)

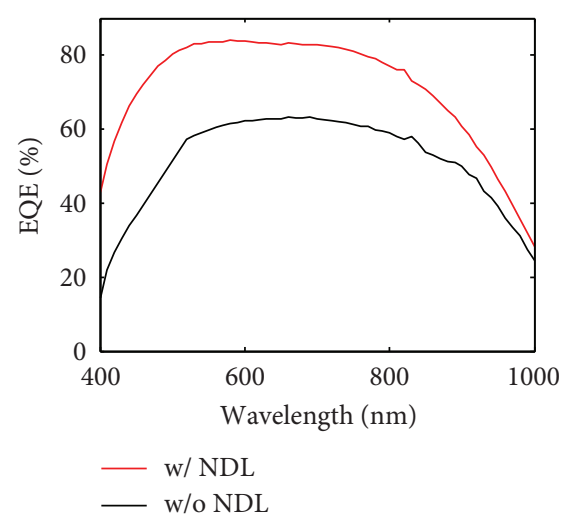

(b)

Figure 7: (a) J-V characteristics and (b) EQE characteristics of the solar cells with NDL (red) and without NDL (black).

contains three layers: a $1.7 \mu \mathrm{m} 1.5 \times 10^{18} \mathrm{~cm}^{-3}$ boron-doped p-type base layer, a $0.9 \mu \mathrm{m} 10^{16} \mathrm{~cm}^{-3} \mathrm{p}^{-}$intrinsic layer, and a $0.3 \mu \mathrm{m} 1.5 \times 10^{19} \mathrm{~cm}^{-3}$ phosphorus-doped $\mathrm{n}^{+}$-type emitter layer.

Second, the NDL was fabricated over the whole sample using the method described in Section $3.700 \mathrm{~nm} \mathrm{SiN}_{\mathrm{x}}$ layer was deposited at $350^{\circ} \mathrm{C}$ using PECVD with $10 \mathrm{~nm} \mathrm{SiO}{ }_{x}$ layer on top (Figure 6(b)). Later, a monolayer of compact silica nanospheres was assembled on top of the $\mathrm{SiO}_{\mathrm{x}}$ thin film using LB method (Figure 6(c)). Next, a combination of $\mathrm{CF}_{4}$ and $\mathrm{O}_{2}$ was used to dry etch the $\mathrm{SiN}_{\mathrm{x}}$ with silica nanopheres as etching masks and followed by $50: 1 \mathrm{HF}$ dip to remove the remaining $\mathrm{SiO}_{\mathrm{x}}$ and silica (Figure 6(d)). The fabricated NDL has the nanodome shape as in Figure 4(a).

Standard 5X projection system optical lithography was used to define the contact region. The top contact region is formed by removing the PECVD $\operatorname{SiN}_{\mathrm{x}}$ with $6: 1$ buffered oxide etchant (BOE) (Figure 6(e)) and followed by evaporation of $200 \mathrm{~nm}$ thick aluminum for the contact. The front contact region is finally formed by lift-off process in acetone. The back contact was formed by directly aluminum evaporation on the back side of the wafer. The schematic of the fabricated solar cell with NDL is shown in Figure 6(f). To evaluate the performance of the NDL, control samples were also fabricated. The control samples have the similar cell structure and fabrication process, but without NDL on top.

The current density-voltage $(\mathrm{J}-\mathrm{V})$ characteristics of the fabricated $2.9 \mu \mathrm{m}$ cells were performed under AM 1.5G 1sun illumination $\left(1000 \mathrm{~W} / \mathrm{cm}^{2}\right)$ at room temperature. A calibrated solar simulator was used to provide the illumination, and the light intensity was monitored using a NREL certificated solar cell. The J-V measurement results of the cells with and without the $\mathrm{SiN}_{\mathrm{x}}$ NDL structures are shown in Figure 7(a), and the key solar cell parameters including short-circuit current density, open-circuit voltage, efficiency, and fill factor are summarized in Table 1.

First of all, the solar cell with NDL achieved a $J_{\mathrm{sc}}$ of $28.15 \mathrm{~mA} / \mathrm{cm}^{2}$, which is $32 \%$ higher than the $J_{\text {sc }}$ of the control cell without NDL. This is due to the antireflection and lighttrapping effect of the NDL. Such effect could also be seen from the results of the external quantum efficiency (EQE)
TABLE 1: Summary of solar cell performance.

\begin{tabular}{lcccc}
\hline & $\begin{array}{c}J_{\mathrm{sc}} \\
\left(\mathrm{mA} / \mathrm{cm}^{2}\right)\end{array}$ & $V_{\mathrm{oc}}(\mathrm{mV})$ & $\begin{array}{c}\text { Fill factor } \\
(\%)\end{array}$ & $\begin{array}{c}\text { Efficiency } \\
(\%)\end{array}$ \\
\hline w/ NDL & 28.15 & 570 & 71.3 & 11.44 \\
w/o NDL & 21.32 & 540 & 69.4 & 8.08 \\
$\begin{array}{l}\text { Relative } \\
\text { improvement }\end{array}$ & $25 \%$ & $6.5 \%$ & $2.7 \%$ & $44 \%$ \\
\hline
\end{tabular}

measurement in Figure 7(b), which was conducted using mechanically chopped monochromatic light with the photocurrent measured using a lock-in amplifier. With NDL, the $\mathrm{EQE}$ is improved from below $60 \%$ to $~ 80 \%$ over a wide range of solar spectrum $(500 \mathrm{~nm}$ to $800 \mathrm{~nm}$ ). However, EQE decreases at wavelength above $800 \mathrm{~nm}$ due to the weak absorption of $\mathrm{c}-\mathrm{Si}$ at such wavelength range, and the improvement with NDL is also smaller there. The $J_{\mathrm{sc}}$ and EQE could be further improved by making a stand-alone ultrathin c-Si solar cell with integrated back reflector [24].

Second, the solar cell with NDL also achieved a $V_{\text {oc }}$ of $570 \mathrm{mV}$, which is $30 \mathrm{mV}$ higher than the $V_{\mathrm{oc}}$ of the control cell without NDL. As $V_{\text {oc }}$ is related to the overall minority carrier recombination inside the solar cells, a higher $V_{\mathrm{oc}}$ indicates that the cell with NDL has a better surface passivation effect while still maintaining the same pn junction quality. Such a surface passivation effect could also be seen from the EQE enhancement at short wavelength $(400 \mathrm{~nm}$ to $500 \mathrm{~nm}$ ) in Figure $7(\mathrm{~b})$. With NDL, the EQE is improved from below $20 \%$ to above $40 \%$ at $400 \mathrm{~nm}$, which is more than $100 \%$ relative improvement. For photons at $400 \mathrm{~nm}$ wavelength, the absorption depth is only $82 \mathrm{~nm}$ [22], which means that most of the photons at $400 \mathrm{~nm}$ are absorbed near the surface and are highly affected by the surface recombination. Therefore, such a huge improvement at $400 \mathrm{~nm}$ EQE not only exhibits the antireflection effect but also demonstrates the surface passivation effect of NDL.

Overall, the solar cell with NDL has an energy conversion efficiency of $11.44 \%$, which is $44 \%$ relatively higher than the efficiency of the control cell without NDL. 


\section{Summary}

To summarize, we have demonstrated a systematical analysis of $\mathrm{SiN}_{\mathrm{x}} \mathrm{NDL}$ for antireflection and light trapping in ultrathin c-Si solar cells. A complete large-area and whole-wafer process to form NDL on thin c-Si is also presented. Also, the NDL has been successfully integrated onto a $40 \mu \mathrm{m}$ thin c-Si layer and an ultrathin c-Si solar cell with $2.9 \mu \mathrm{m}$ absorber. From the simulation and experiment results, a wide-spectrum and wide-angle antireflection and light-trapping effect has been achieved using NDL. Together with the good surface passivation effect of $\mathrm{SiN}_{\mathrm{x}}$, NDL exhibits great potential to produce high-efficiency and low-cost ultrathin c-Si solar cells.

\section{Conflicts of Interest}

The authors declare that they have no conflicts of interest.

\section{Acknowledgments}

This work was supported by the Bay Area Photovoltaic Consortium (BAPVC) and the Global Climate and Energy Project (GCEP) at Stanford University. The authors acknowledge the Stanford Nanofabrication Facility (SNF) for the use of the processing facilities, Center on Nanostructuring for Efficient Energy Conversion (CNEEC) for the use of characterization facilities, and Solexel Inc. for providing the $40 \mu \mathrm{m} \mathrm{c}-\mathrm{Si}$ layer. Yusi Chen would like to acknowledge the funding support from Applied Materials Inc. through the SystemX FMA program. Jieyang Jia would like to acknowledge the funding support from the Stanford Graduate Fellowship (SGF).

\section{References}

[1] E. Garnett and P. D. Yang, "Light trapping in silicon nanowire solar cells," Nano Letters, vol. 10, no. 3, pp. 1082-1087, 2010.

[2] P. J. Poole, D. Dalacu, J. Lefebvre, and R. L. Williams, "Selective epitaxy of semiconductor nanopyramids for nanophotonics," Nanotechnology, vol. 21, no. 29, article 295302, 2010.

[3] D. Liang, Y. Huo, Y. Kang et al., "Optical absorption enhancement in freestanding GaAs thin film nanopyramid arrays," Advanced Energy Materials, vol. 2, no. 10, pp. 1254-1260, 2012.

[4] J. Zhu, C. M. Hsu, Z. Yu, S. Fan, and Y. Cui, "Nanodome solar cells with efficient light management and self-cleaning," Nano Letters, vol. 10, no. 6, pp. 1979-1984, 2010.

[5] J. Zhu, Z. Yu, G. F. Burkhard et al., "Optical absorption enhancement in amorphous silicon nanowire and nanocone arrays," Nano Letters, vol. 9, no. 1, pp. 279-282, 2009.

[6] L. Dong, Y. Kang, Y. Huo, Y. Chen, Y. Cui, and J. S. Harris, "High-efficiency nanostructured window GaAs solar cells," Nano Letters, vol. 13, no. 10, pp. 4850-4856, 2013.

[7] F. Khan, S. H. Baek, J. Kaur, I. Fareed, A. Mobin, and J. H. Kim, "Paraboloid structured silicon surface for enhanced light absorption: experimental and simulative investigations," Nanoscale Research Letters, vol. 10, no. 1, p. 376, 2015.

[8] Y. Kang, D. Liang, Y. Huo et al., "Design and fabrication of nano-pyramid GaAs solar cell," in Proceedings 39th IEEE Photovoltaic Specialists Conference, pp. 3321-3323, Tampa, Florida, USA, 2013.
[9] ITRPV Working Group, International Technology Roadmap for Photovoltaic, SEMI, 2014, http://www.itrpv.net/.

[10] D. M. Powell, R. Fu, K. Horowitz, P. A. Basore, M. Woodhouse, and T. Buonassisi, "The capital intensity of photovoltaics manufacturing: barrier to scale and opportunity for innovation," Energy \& Environmental Science, vol. 8, no. 12, pp. 3395-3408, 2015.

[11] M. S. Branham, W. C. Hsu, S. Yerci et al., "15.7\% efficient $10-\mu \mathrm{m}$-thick crystalline silicon solar cells using periodic nanostructures," Advanced Materials, vol. 27, no. 13, pp. 2182-2188, 2015.

[12] S. Jeong, M. D. McGehee, and Y. Cui, "All-back-contact ultra-thin silicon nanocone solar cells with $13.7 \%$ power conversion efficiency," Nature Communications, vol. 4, no. 4, p. 2950, 2013.

[13] K. J. Yu, J. S. Park, Y. R. Lee et al., "Light trapping in ultrathin monocrystalline silicon solar cells," Advanced Energy Materials, vol. 3, no. 11, pp. 1401-1406, 2013.

[14] J. Oh, H.-C. Yuan, and H. M. Branz, "An 18.2\%-efficient black-silicon solar cell achieved through control of carrier recombination in nanostructures," Nature Nanotechnology, vol. 7, no. 11, pp. 743-748, 2012.

[15] L. M. Fraas and L. D. Partain, Solar Cells and their Applications, vol. 236, John Wiley \& Sons, New York, USA, 2010.

[16] A. G. Aberle, "Surface passivation of crystalline silicon solar cells: a review," Progress in Photovoltaics: Research and Applications, vol. 8, no. 5, pp. 473-487, 2000.

[17] J. Schmidt, M. Kerr, and A. Cuevas, "Surface passivation of silicon solar cells using plasma-enhanced chemical-vapourdeposited SiN films and thin thermal SiO2/plasma SiN stacks," Semiconductor Science and Technology, vol. 16, no. 3, p. 164, 2001.

[18] C. M. Hsu, S. T. Connor, M. X. Tang, and Y. Cui, "Wafer-scale silicon nanopillars and nanocones by Langmuir-Blodgett assembly and etching," Applied Physics Letters, vol. 93, no. 13, pp. 133109-133109-3, 2008.

[19] B. O. Dabbousi, C. B. Murray, M. F. Rubner, and M. G. Bawendi, "Langmuir-Blodgett manipulation of size-selected Cdse nanocrystallites," Chemistry of Materials, vol. 6, no. 2, pp. 216-219, 1994.

[20] B. E. E. Kastenmeier, P. J. Matsuo, J. J. Beulens, and G. S. Oehrlein, "Chemical dry etching of silicon nitride and silicon dioxide using CF4/O2/N2 gas mixtures," Journal of Vacuum Science \& Technology a, vol. 14, no. 5, pp. 28022813, 1996.

[21] C. Reyes-Betanzo, S. A. Moshkalyov, J. W. Swart, and A. C. S. Ramos, "Silicon nitride etching in high- and low-density plasmas using SF6/O2/N2 mixtures," Journal of Vacuum Science \& Technology a: Vacuum, Surfaces, and Films, vol. 21, no. 2, pp. 461-469, 2003.

[22] M. A. Green and M. J. Keevers, "Optical properties of intrinsic silicon at $300 \mathrm{~K}$," Progress in Photovoltaics: Research and Applications, vol. 3, no. 3, pp. 189-192, 1995.

[23] Y. Chen, Y. Kang, Y. Huo et al., "Nanostructured dielectric layer-a new approach to design nanostructured solar cells," in 2014 IEEE 40th Photovoltaic Specialist Conference (PVSC), Denver, Colorado, USA, 2014.

[24] K. X. Wang, Z. Yu, V. Liu, Y. Cui, and S. Fan, "Absorption enhancement in ultrathin crystalline silicon solar cells with antireflection and light-trapping nanocone gratings," Nano Letters, vol. 12, no. 3, pp. 1616-1619, 2012. 

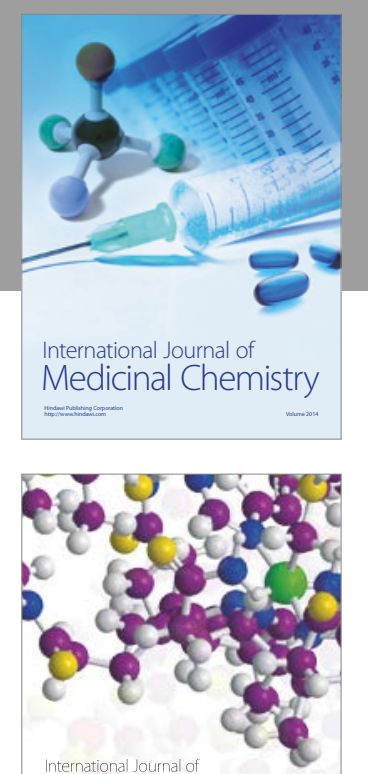

Carbohydrate Chemistry

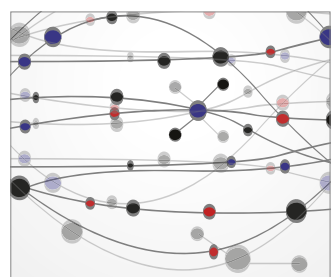

The Scientific World Journal
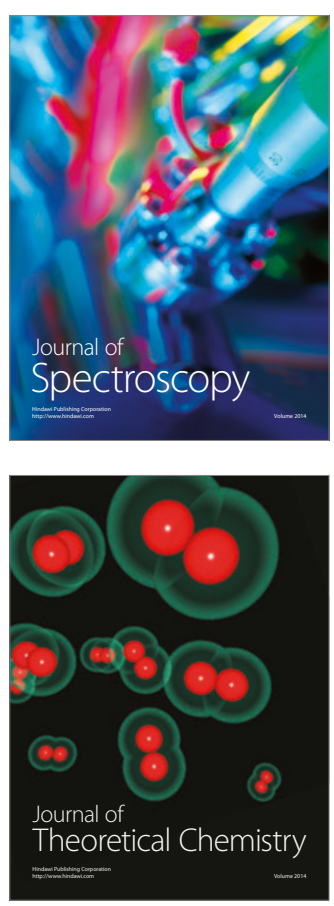
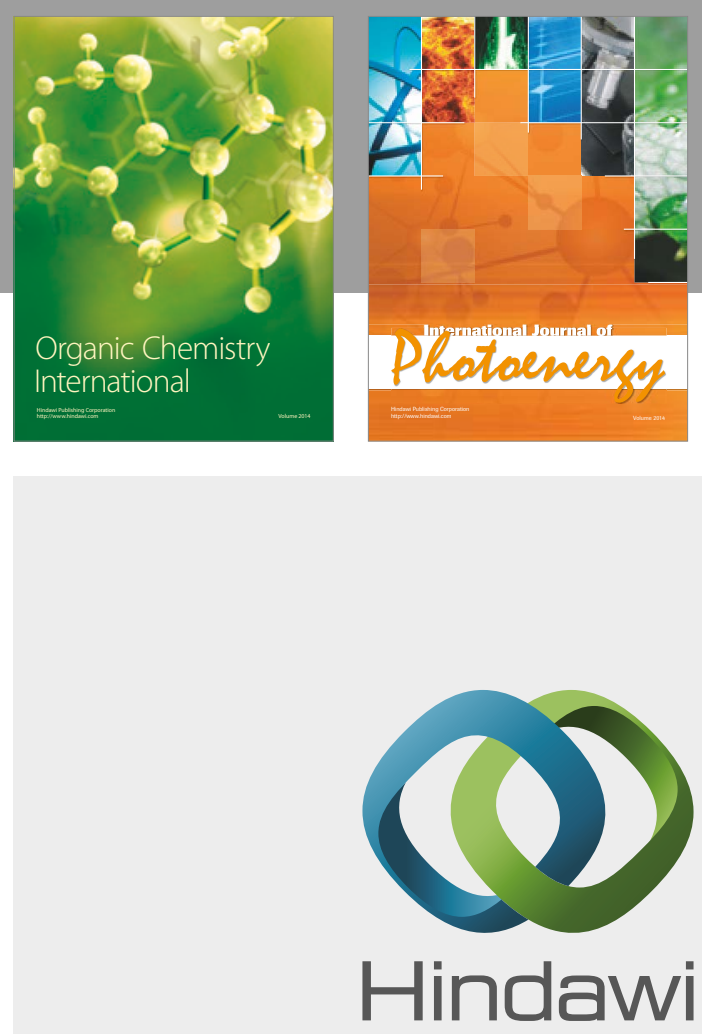

Submit your manuscripts at

https://www.hindawi.com

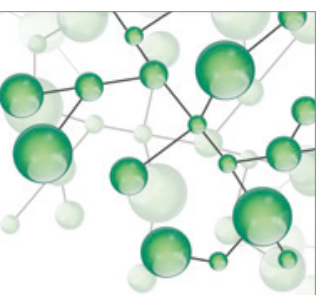

International Journal of

Inorganic Chemistry

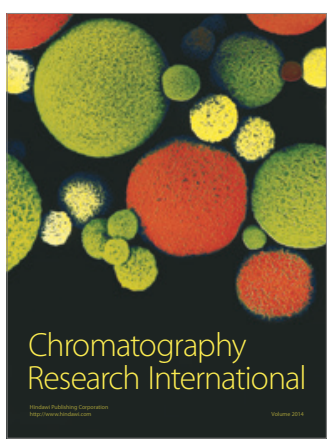

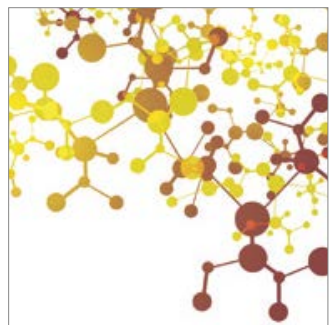

Applied Chemistry
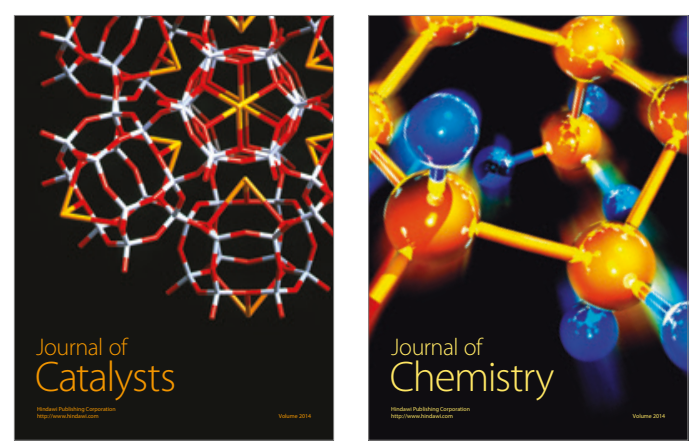
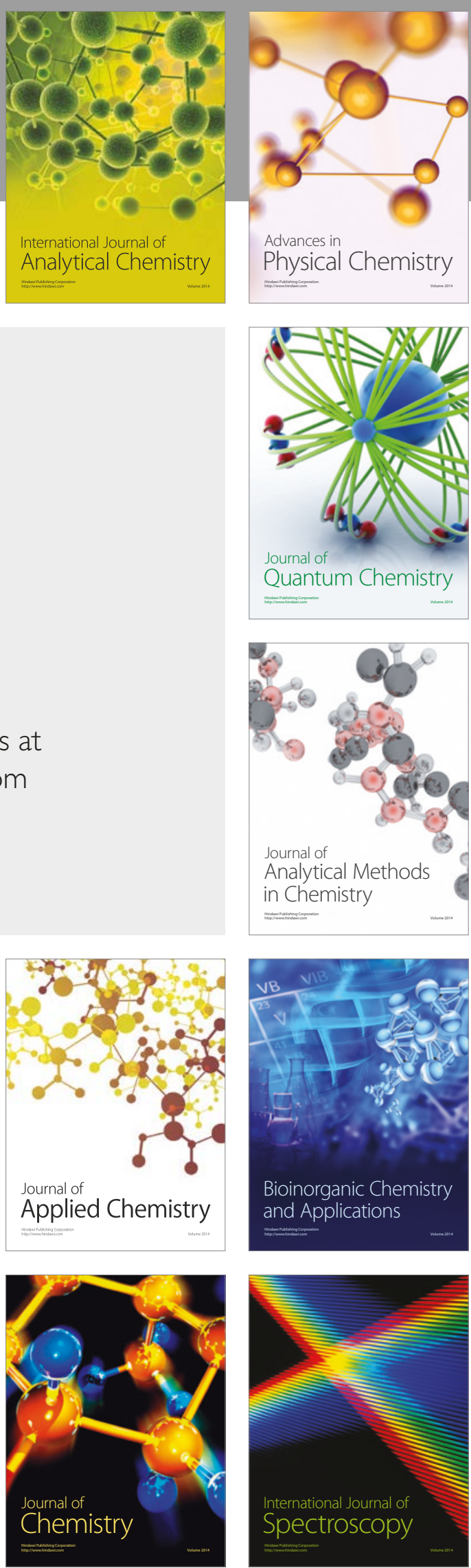